\title{
PARTISIFASI PETANI DALAM KEGIATAN PENYULUHAN USAHATANI PADI SAWAH SISTEM TANAM JAJAR LEGOWO DI KABUPATEN LOMBOK BARAT
}

\author{
MADE SUMA WEDASTRA ${ }^{1)}$, I DEWA GEDE SUARTA ${ }^{2)}$ \\ Program Studi Agribinis Kampus Mataram UNMAS Denpasar \\ e-mail : ${ }^{1)}$ madesumawedastra17@mail.com ${ }^{2)}$ dsuartha@ymail.com
}

\begin{abstract}
ABSTRAK
Usahatani padi sawah dengan system tanam jajar legowo menyebabkan adanya kenaikan produksi yang semula 6 ton/hektar menjadi 8,8 ton/hektar, namun sampai saat ini masih belum semua petani yang mengadopsi teknologi tersebut.

Penelitian ini dilaksanan di Kabupaten Lombok Barat dengan teknik survai, dengan analisis data secara deskriptif. Hasil penelitian menunjukkan bahwa : partisifasi petani dalam kegiatan penyuluhan usahatani padi sawah dengan system tanam jajar legowo tergolng tinggi, yaitu dengan tingkat partifasi 161,25.

Beberpa kendala yang dihadapi petani dalam kegiatan penyuluhan adalah diantaranya adalah sebagai berikut: berbenturan dengan kesibukan lain, adanya kejenuhan mengikuti penyuluhan karena membuang waktu, pemberain materi tidak sesuai dengan pola tanam yang ditanam petani dan manfaatnya dirasakan masih kurang. Masih banyak petani yang tidak mengadopsi teknologi tersebut, dengan alasan bahwa : menanam dengan system tanam jajar memelukan waktu yang lebih banyak, membutuhkan benih yang lebih banyak, memerlukan pupuk dan tenanga kerja yang lebih banyak akhirnya berdampak pada biaya yang dkeluarkan oleh banyak.

Untuk meningkatkan partifasi petani dalam kegiatan penyuluhan, perlu pembinaan dan pelatihan yang lebih intensif oleh petugas penyuluh lapangan (PPL), sehingga dapat merubah prilaku petani dan mau mengadopsi teknolgi tersebut
\end{abstract}

Kata kunci : Partifasi, Penyuluhan, usahatani, sistem tanam, jajar legowo

\section{ABSTRACT}

Lowland rice farming with jajar legowo's planting system causes an increase in production which is originally 6 tons / hectare to 8.8 tons / hectare, but until now not all farmers have adopted the technology.

This research is conducted in West Lombok Regency with survey techniques, with descriptive data analysis. The results show that: the participation of farmers in the extension activities of paddy farming with jowo legowo's planting system is quite high in number with level of participation is 161.25

Some of the obstacles faced by farmers in extension activities are as follows: collide with other activities, there is boredom in participating in counseling because they think it wastes time, the delivery of material is not in accordance with the planting patterns planned by farmers and the benefits are still lacking. There are still many farmers who do not adopt the technology, with the reason that: planting with a row planting system requires more time, requires more seeds, requires more fertilizer and more work conditions, ultimately impacting the costs incurred by the farmers.

To increase farmers' participation in extension activities, more intensive training is needed by field extension workers (PPL), so that they can change the behavior of farmers and want to adopt the technology.

Keywords: Participation, Counseling, farming, jajar legowo's planting system 


\section{PENDAHULUAN}

\section{Latar Belakang}

Salah satu agribsinis yang paling urgen untuk mendapat perhatian adalah beras (padi). Hal ini disebabkan bahwa beras merupakan salah satu komoditas yang mempunyai dampak strategis baik secara ekonomi, sosial maupun politik dan sampai saat ini masih merupakan tulang punggung perekonomian keluarga tani dan perekonomian pedesaan.

Jumlah beras yang di butuhkan terus meningkat, yang di sebabkan oleh laju pertumbuhan penduduk yang semakin meningkat yang di ikuti oleh permintaan beras yang semakin meningkat pula. Selain itu harga beras cenderung meningkat, sehingga di perlukan usaha-usaha untuk meningkatkan produksi tanaman pangan khususnya beras.

Pada periode tahun 2001-2006 peningkatan produktivitas padi memberikan konstribusi 56,1 \%, sedangkan peningkatan luas panen dan interaksi keduanya memberikan konstribusi masing-masing $26,3 \%$ dan $17,5 \%$ terhadap peningkatan luas produksi padi.

Sejak awal tahun 2007 dan selanjutnya produksi padi meningkat 5 persen / tahun hingga tahun 2009 pemerintah telah bertekad untuk meningkatkan produksi beras 2 juta ton pada tahun 2007 dan 10 juta ton beras di tahun 2014. Untuk mencapai target atau sasaran tersebut maka di luncurkan program peningkatan produksi beras nasional ( $\mathrm{P} 2 \mathrm{BN})$ dengan mengimplementasikan 4 strategi (Badan Litbang pertanian 2007, Purwanto, S., 2008), yaitu : peningkatan produktivitas, perluasan areal tanam, pengamanan produksi, kelembagaan dan pembiayaan serta peningkatan koordinasi.

Berbagai upaya peningkatan produksi dan produktivitas usahatani padi telah dilaksanakan, antara lain melalui Sekolah Lapangan Pengelolaan Tanaman Terpadu (SL-PTT) sejak tahun 2008 dan melalui PTT atau peningkatan mutu intensifikasi pada tahun-tahun sebelumnya. Pelaksanaan SL-PTT sebagai pendekatan dalam mendorong peningkatan produksi padi nasional telah terbukti mengungkit pencapaian produksi, namun ke depan dengan berbagai tantangan yang lebih beragam maka diperlukan penyempurnaan dan peningkatan kualitas pada tatanan perencanaan dan operasionalisasi di lapangan (Ridwan dkk, 2019). Untuk hal tersebut, maka sejak tahun 2015 upaya peningkatan produksi padi difokuskan pada kawasan tanaman pangan, melalui Gerakan Penerapan Pengelolaan Tanaman Terpadu (GP-PTT) dengan fasilitasi bantuan sarana produksi (saprodi), tanam jajar legowo dan pertemuan kelompok pada seluruh areal program GPPTT sebagai instrument stimulan disertai dengan dukungan pembinaan, pengawalan dan pemantauan oleh berbagai pihak.

Sejalan dengan fasilitasi bantuan yang diberikan pemerintah pada seluruh areal program, maka luas GP-PTT Padi tahun 2015 adalah 350.000 ha, yang dialokasikan pada kawasan padi dan non kawasan padi dan terinci atas: Kawasan Padi inbrida seluas 75.000 ha, non Kawasan padi hibrida seluas 225.000 ha dan non Padi hibrida seluas 50.000 ha. Dalam GP-PTT petani dapat langsung menerapkan teknologi budidaya spesifik lokasi yang merupakan hasil rekomendasi (Ridwan, dkk, 2019).

Banyak yang telah dilaksanakan pemerintah dalam usahanya untuk meningkatkan produksi padi (beras), namun tetap tidak bisa memenuhi permintaan penduduk dalam negeri

Rata-rata produktifitas padi di kabupaten Lombok Barat baru mencapai 53,81 kwt/ha Gkp (BPS, 2018). Hasil ini terbilang masih rendah dan masih bisa di tingkatkan. Salah satu penyebab masih rendahnya produktifitas padi karena petani masih banyak petani melaksanakan penanaman padi dengan jarak tanam tidak teratur. Penanaman dengan jarak tanam yang tidak teratur menyebabkan populasi tanam per satuan luas masih kurang, yaitu rata-rata kurang dari 200.000 rumpun/ha.

Selain penanaman dengan jarak yang tidak teratur menyebabkan dapat menstimulir serangan OPT dan menyulitkan pemeliharaan. Oleh karna itu populasi perlu ditingkatkan dengan penanaman (tandur jajar) dengan jarak tanam yang teratur yang di anjurkan dengan jarak $20 \mathrm{X} 20 \mathrm{~cm}$ populasi dapat ditingkatkan menjadi 250.000 rumpun/ha dan 333.000 rumpun/ha apabila penanaman dengan sisten tandur jajar legowo. Dengan cara tanam system ini adanya peningkatan hasil yang semula 6 ton/hektar menjadi 8,8 tom/hektar (Umiarsih, 2012., Permana, 1998).

Dalam upaya pencapaian target program peningkatan produksi beras nasional (P2BN) pemerintah dalam hal ini Departemen Pertanian melalui badan pengembangan dan penelitian telah banyak mengeluarkan rekomendasi untuk diaplikasikan oleh petani. Salah satu rekomendasi tersebut adalah penerapan sistem tanam yang baik dan benar melalui pengaturan jarak tanam yang dikenal dengan sisten tanam jajar legowo. (Umiarsih, 2012., Permana, 1998). 
Sistem tanam jajar legowo merupakan salah satu inovasi teknologi yang diperkenalkan dalam usaha untuk meningkatkan produktivitas padi. Prinsip dari sistem tanam jajar legowo adalah meningkatkan populasi tanaman dengan mengatur jarak tanam sehingga pertanaman akan memiliki barisan tanaman yang diselingi oleh barisan kosong dimana jarak tanam pada barisan pinggir setengah kali jarak tanam antar barisan, selain itu tanaman yang berada dipinggir diharapkan memberikan produksi yang lebih tinggi dan kualitas gabah yang lebih baik, mengingat pada sistem tanam jajar legowo terdapat ruang terbuka seluas 25$50 \%$, sehingga tanaman dapat menerima sinar matahari secara optimal yang berguna dalam proses fotosintesis.

Di Kabupaten Lombok Barat sebenarnya sudah lama dikenalkan tentang paket teknologi sisten tanam jajar legowo, namun sampai saat ini masih belum banyak petani yang menerapkanya, dibandingan dengan tanam jajar biasa atau tidak teratur. Hal ini bisa dimaklumi bahwa adopsi teknologi baru, tentu membawa dampak secara social maupun ekonomis, selain dampak lingkungan dan agro teknologinya. Secara social terbatasnya penggunaan teknologi baru mungkin karena belum siapnya petani menggunakan teknologi tersebut, sebagai akibat dari pengetahuan tentang teknologi tersebut masih kurang. Secara ekonomis apakah teknologi itu menguntungkan atau tidak. Terkait dengan dampak lingkungan apakah tidak merusak lingkungan yang ada dan secara agro teknologi apakah bisa diterapkan disemua tempat.

Kegiatan penyuluhan sebagai salah satu kegiatan kunci dalam peningkatan produksi pertanian, harus pula meningkatkan prestasinya secara terus menerus. Tanpa penyuluhan yang efektif agak sulit mencapai laju peningkatan produksi tanaman pangan secara kontinyu, karena itu perlu ditata mekanisme penyuluhan dan adopsi inovasi baru secara lebih merata kepada seluruh petani, sehingga dengan ketrampilan dan kemampuan pertain yang meningkat akan diperoleh peningkatan produksi sekaligus pendapatan petani. Untuk mewujudkan target produksi dan meratanya adopsi inovasi, kegiatan penyuluhan harus diselenggarakan secara baik, teratur terarah dan dinamis (Totok Mardikanto, 2009).

Menurut Made Suma Wedastra (2009), bahwa seringkali dalam memberikan penyuluhan kepada petani, proses komonikasi itu tidak berjalan dengan lancar, bahkan sering pula sama sekali tidak berjalan. Hal ini disebabkan oleh bentuk hubungan antara komonikator dengan komikan. Jika diantara keduanya telah terjadi penyesuaian, maka komonikasi akan bertambah lancar. Selain itu pula dalam proses komonikasi dipengaruhi oleh lingkungan, semakin cepat konomikator dinilai sebagai seorang diantara anggota kelompok masyarakat (in group) oleh petani, maka apa yang disampaikkan akan lebih cepat diterima. Untuk itu seorang penyuluh hendaknya menanamkan kepercayaan diantara petani. Dipercaya bahwa ya seorang penyuluh dan dipercaya ia sebagai anggota masyarakat yang baik.

\section{Rumusan Masalah}

Dalam usahatani padi di Kabupaten Lombok Barat, ada beberapa hal yang menjadi tantangan, salah satunya yaitu bagaimana upaya yang harus dilakukan untuk mendapatkan hasil produksi padi yang tinggi. Namun untuk mewujudkan upaya tersebut masih terkendala, karena sampai saat ini masih jarang petani di lapangan yang menanam dengan sistem tanam jajar legowo. Padahal dengan system ini, ada kenaikan produksi 2,8 ton/hektar yang semula mencapai 6 ton/hektar menjadi 8,8 ton/hektar.

Belum banyaknya masyarakat petani yang menerapkan system tanam jajar legowo, ada beberapa sebab, salah satunya adalah partisifasi petani untuk melaksanakan anjuran penyuluh tentang penerapan system taman jajar legowo yang masih rendah.

Partisifasi petani dalam penyuluhan system tanam jajar legowo dipengaruhi oleh kondisi sosial ekonomi yang berbeda, sehingga partisifasi masyarakat (petani) juga berbeda.

Dari partsifasi petani, maka dengan jelas bahwa peran serta petani menjadi sedemikian penting dalam setiap bentuk kegiatan, yang mana dengan dukungan masyarakat tani yang saling berinteraksi senanantiasa memberi harapan kearah berhasilnya suatu kegiatan, dalam hal ini kegiatan penyuluhan sistem tanam jajar legowo

\section{Tujuan dan Manfaat Penelitian}

Tujuan dari penelitian ini adalah untuk mengetahui: partipasi petani dalam kegiatan penyuluhan pertanian pada usahatani padi sistem tanam jajar legowo di Kabupaten Lombok Barat dan kendala-kendala yang mempengaruhi partisipasi petani dalam kegiatan penyuluhan pada usahatani padi sistem tanam jajar legowo di Kabupaten Lombok Barat. Diharapkan hasil penelitian ini sebagai bahan pertimbangan bagi pengambil kebijakan dalam pengembangan produksi padi. 


\section{METODE PENELITIAN}

\section{Jenis Penelitian}

Jenis penelitian yang digunakan dalam penelitian ini adalah jenis penelitian deskriptif yaitu, jenis yang tertuju pada pemecahan masalah yang ada pada saat sekarang dengan mengumpulkan dan menyusun, menganalisis, menjelaskan dan menarik kesimpulan (Winarno Surakhman, 2010).

\section{Lokasi Penelitian}

Penentuan lokasi (sampel desa) dilakukan secara sengaja atau purposive sampling, yaitu di Desa Narmada, Kecamatan Narmada dan Desa Gerung Kecamatan Gerung. Kabupaten Lombok Barat, dengan pertimbangan pada musim tanam 2019 di dua desa tersebut menerapkan usahatani padi system tanam jajar legowo.

\section{Penentuan Responden}

Jumlah responden ditentukan secara proposional random sampling, dimana jumlah sampel berdasarkan atas jumlah populasi yang ada dimasing-masing desa. Pada penelitian ini ditentukan jumlah sampel 60 orang, dimana 38 orang petani dari Desa Narmada dan 22 orang petani dari Desa Gerung.

\section{Jenis dan Sumber Data}

Data yang di perlukan dalam penelitian ini adalah data primer dan data sekunder. Data primer di peroleh dari hasil wawancara langsung dengan petani responden yang menerapkan sistem tanam jajar legowo. Sedangkan data sekunder diperoleh dari sumber-sumber lain seperti buku-buku yang relevan serta dari instansi terkait, seperti, Perpustakaan Daerah Kabupaten Lombok Barat, BPS (Badan Pusat Statistik) Kabupaten Lombok Barat, Kantor Dinas Pertanian Kabupaten Lombok Barat, dan Kantor Kecamatan Narmada.

\section{Teknik dan Alat Pengumpulan Data}

Teknik pengumpulan data yang digunakan dalam penelitian ini adalah : Observasi yaitu teknik pengumpulan data dengan mengadakan pengamatan langsung ke lokasi penelitian dan Interviu (wawancara), yaitu mengadakan wawancara langsung dengan responden yang berpedoman dengan daftar pertanyaan (kuisioner). Sedangkan alat pengumpulan data yang digunakan adalah checklist (daftar pertanyaan ) yang berkaitan dengan data-data yang sesuai dengan penelitian (Sofyan Effendi dan Masri Singarimbun, 2010).

\section{Identifikasi Variabel}

Variabel yang diukur dalam penelitian ini adalah : tahap perencanaan, pelaksanaan, tahap penyebaran informasi dan tahap evaluasi.

Adapun yang diukur pada tahap perencanaan adalah :

1). Keberadaan rencana kerja, 2). Kehadiran petani dalam menyusun rencana kerja,3). proses penyusunan rencana kerja, 4).Keaktifan petani mengeluarkan pendapat/ide, 5).Tanggapan terhadap ide yang diberikan.

Masing-masing pertanyaan diberi skor 1-3 sehingga jumlah skor pada tahap perencanaan adalah 5-15 Pada tahap pelaksanaan yang diukur adalah :

1). Menyangkut proses pelaksanaan penyuluhan pertanian yaitu : a).Pertemuan individu, b). pertemuan kelompok,c). pertemuan masal, d).demontrasi usahatani, e)..pemberian leaflet, f). pemberian famlet, g). pemberian brosur,

2). Substansi kegiatan penyuluhan yang terdiri atas : a). persiapan lahan, b). Pengadaan peralatan, c). benih yang digunakan, d). jumlah yang digunakan, e). asal benih yang digunakan, f). pupuk yang digunakan, g). jumlah pupuk yang digunakan, h). jenis pestisida yang digunakan, i). Jumlah pestisida yang digunakan.

Masing-masing pertanyaan diberi skor 1-3 sehingga jumlah skor pada tahap kegiatan penyuluhan adalah $16-48$ 
Adapun yang diukur pada tahap Penyebarluasan informasi yang diukur adalah : a). Alat bantu penyuluhan, b). Metode penyuluhan, c). Media penyuluhan

Masing-masing pertanyaan diberi skor 1-3 sehingga jumlah skor pada tahap Penyebarluasan informasi adalah 3-9

Adapun yang diukur pada tahap evaluasi yang diukur adalah : a). Penilaian kegiatan, b). Evaluasi keberhasilan kegiatan penyuluhan. Masing-masing pertanyaan diberi skor 1-3 sehingga jumlah skor pada tahap evaluasi adalah 2-6

Untuk mengetahui tingkat pertisifasi petani dalam setiap kegiatan penyuluhan dilakukan pengelompokan partisifasi dengan menggunaka interval;

$$
\mathrm{I}=\frac{\sum \mathrm{TST}-\sum \mathrm{TSt}}{\sum \text { kategori }}
$$

Keterangan I $=$ Interval, $\mathrm{TST}=$ Total Skor Tertinggi, TSt $=$ Total Skor Terendah, Kategori $=$ Tinggi, Sedang, Rendah.

Partisifasi petani dalam kegiatan penyuluhan : a). Dikatakan rendah, jika nilai skor : $140-147$. b).Dikatakan sedang, jika skor : 148-155 c). Dikatakan tinggi, jika skor : 156-163

Untuk menganalisis kendala-kendala dalam pelaksanakan penyuluhan dengan cara menginventarisir kendala-kendala yang dihadapi petani, kemudian ditabulasi dan dianalisis secara deskriptif

\section{HASIL DAN PEMBAHASAN}

\section{Partisifasi Petani dalam Kegiatan Penyuluhan Usahatani Padi Sistem Tanam Jajar Legowo}

Sebaran Petani responden menurut tingkat partifasi petani dalam kegiatan penyuluhan pada usahatani padi sawah sistem tanam jajar legowo di Kabupaten Lombok Barat dapat dilihat pada Tabel 1.

Tabel 1. Sebaran Petani dalam Partifasi Kegiatan Penyuluhan Usahatani Padi Sistem Tanam Jajar Legowo di Kabupaten Lombok Barat

\begin{tabular}{|l|l|c|c|}
\hline No & Tingkat Partisifasi Petani & $\begin{array}{l}\text { Jumlah Responden } \\
(\text { Orang })\end{array}$ & Persentase (\%) \\
\hline 1 & Partisifasi Tinggi & 45 & 75 \\
\hline 2 & Partisifasi Sedang & 11 & 18,34 \\
\hline 3 & Partisifasi Tinggi & 4 & 6,67 \\
\hline
\end{tabular}

Sumber : Data primer diolah, 2020

Tabel 1 di atas menujukkan bahwa sebagian besar petani yakni 45 orang $(75 \%)$ berpartifasi tinggi dalam kegiatan penyuluhan pada usahatani sistem tanam jajar legowo, 11 orang $(18,34 \%)$ bepartisifasi sedang dan 4 orang $(6,67 \%)$ berpartifasi rendah.

Untuk melihat sebaran partisifasi petani dalam kegiatan penyuluhan dapat dilihat pada Tabel 2. 
Tabel 2. Sebaran Partisifasi Petani dalam Kegiatan Penyuuhan Berdasarkan atas Aspek yang dinilai

\begin{tabular}{|c|c|c|c|c|c|c|c|c|}
\hline \multirow[t]{3}{*}{$\mathrm{No}$} & \multirow[t]{3}{*}{ No } & \multirow[t]{3}{*}{ Aspek yang dinilai } & \multicolumn{6}{|c|}{ Partisifasi } \\
\hline & & & \multicolumn{2}{|c|}{ Tinggi } & \multicolumn{2}{|c|}{ Sedang } & \multicolumn{2}{|c|}{ Rendah } \\
\hline & & & \begin{tabular}{|c|} 
Jumlah \\
(org)
\end{tabular} & $\%$ & $\begin{array}{r}\text { Jumlah } \\
\text { (Org) }\end{array}$ & $\%$ & \begin{tabular}{|l|l|}
$\begin{array}{l}\text { umlah } \\
(\text { Org })\end{array}$ \\
\end{tabular} & $\%$ \\
\hline \multirow[t]{7}{*}{1} & \multicolumn{8}{|c|}{ Perencanaan } \\
\hline & $\mathrm{a}$ & Keberadaan Rencana Kerja & 53 & 88.33 & 5 & 8.33 & 2 & 3.33 \\
\hline & $\mathrm{b}$ & Kehadiran Petani dalam Menyusun Rencana Kerja & 57 & 95.00 & 2 & 3.33 & 1 & 1.67 \\
\hline & $\mathrm{c}$ & Proses Penyusunan rencana Kerja & 40 & 66.67 & 15 & 25.00 & 5 & 8.33 \\
\hline & $\mathrm{d}$ & Aktif Mengemukakan Pendapat & 39 & 65.00 & 11 & 18.33 & 10 & 16.67 \\
\hline & $\mathrm{e}$ & Tanggapan terhadap ide yang diberikan & 48 & 80.00 & 9 & 15.00 & 3 & 5.00 \\
\hline & \multicolumn{2}{|c|}{ Rata-rata } & 48 & $\mathbf{8 0 , 0 0}$ & 8 & 13,33 & 4 & 6,67 \\
\hline \multirow[t]{9}{*}{$2 a$} & \multicolumn{8}{|c|}{ Pelaksanaan } \\
\hline & $\bar{a}$ & Pertemuan Individu & 50 & 83.33 & 8 & 13.33 & 2 & 3.33 \\
\hline & $\mathrm{b}$ & Pertemuan kelompok & 48 & 80.00 & 9 & 15.00 & 3 & 5.00 \\
\hline & $\mathrm{c}$ & Pertemuan Masal & 48 & 80.00 & 8 & 13.33 & 4 & 6.67 \\
\hline & $\mathrm{d}$ & Demontrasi Usahatani & 52 & 86.67 & 2 & 3.33 & 6 & 10.00 \\
\hline & $\mathrm{e}$ & Peberian leaflet & 40 & 66.67 & 18 & 30.00 & 2 & 3.33 \\
\hline & $\mathrm{f}$ & Pemberian famlet & 38 & 63.33 & 17 & 28.33 & 5 & 8.33 \\
\hline & $\mathrm{g}$ & Pemberian Brosur & 40 & 66.67 & 19 & 31.67 & 1 & 1.67 \\
\hline & \multicolumn{2}{|c|}{$\frac{1}{\text { Rata-rata }}$} & 45 & 75,00 & 12 & 20,00 & 3 & 5,00 \\
\hline \multirow[t]{11}{*}{$2 \mathrm{~b}$} & \multicolumn{8}{|c|}{ Substansi Kegiatan penyuluhan } \\
\hline & $\mathrm{a}$ & persiapan lahan & 40 & 66.67 & 12 & 20.00 & 8 & 13.33 \\
\hline & $\mathrm{b}$ & Pengadaan peralatan & 35 & 58.33 & 20 & 33.33 & 5 & 8.33 \\
\hline & $\mathrm{c}$ & benih yang digunakan & 40 & 66.67 & 10 & 16.67 & 10 & 16.67 \\
\hline & $\mathrm{d}$ & jumlah yang digunakan & 50 & 83.33 & 8 & 13.33 & 2 & 3.33 \\
\hline & $\mathrm{e}$ & asal benih yang digunakan & 45 & 75.00 & 12 & 20.00 & 3 & 5.00 \\
\hline & $\mathrm{f}$ & pupuk yang digunakan & 50 & 83.33 & 8 & 13.33 & 2 & 3.33 \\
\hline & $\mathrm{g}$ & jumlah pupuk yang digunakan, & 50 & 83.33 & 6 & 10.00 & 4 & 6.67 \\
\hline & $\mathrm{h}$ & jenis pestisida yang digunakan & 50 & 83.33 & 7 & 11.67 & 3 & 5.00 \\
\hline & i & Jumlah pestisida yang digunakan & 40 & 66.67 & 12 & 20.00 & 8 & 13.33 \\
\hline & \multicolumn{2}{|c|}{ Rata-rata } & 44 & 73,34 & 11 & 18,34 & 5 & $\mathbf{8 , 3 3}$ \\
\hline \multirow[t]{5}{*}{3} & \multicolumn{8}{|c|}{ Penyebarluasan informasi } \\
\hline & $\mathrm{a}$ & Alat bantu penyuluhan & 35 & 58.33 & 17 & 28.33 & 8 & 13.33 \\
\hline & $\mathrm{b}$ & Metode penyuluhan & 45 & 75.00 & 8 & 13.33 & 7 & 11.67 \\
\hline & $\mathrm{c}$ & Media penyuluhan & 50 & 83.33 & 8 & 13.33 & 2 & 3.33 \\
\hline & \multicolumn{2}{|c|}{ Rata-rata } & 43 & 71,67 & 11 & 18,33 & 6 & 10,00 \\
\hline \multirow[t]{4}{*}{4} & \multicolumn{8}{|c|}{ Tahap evaluasi } \\
\hline & $\mathrm{a}$ & Penilaian kegiatan, & 40 & 66.67 & 18 & 30.00 & 2 & 3.33 \\
\hline & $\mathrm{b}$ & Evaluasi keberhasilan kegiatan penyuluhan. & 50 & 83.33 & 8 & 13.33 & 2 & 3.33 \\
\hline & \multicolumn{2}{|c|}{ Rata-rata } & 45 & 75,00 & 13 & 21,67 & 2 & 3,33 \\
\hline
\end{tabular}

Sumber: Data primer diolah, 2020

Dari Tabel 2 dapat dilihat bahwa sebagian besar petani yaitu 48 orang petani (80\%) berpartipasi tinggi dalam perencanaan usahatani padi system tanam jajar legowo, 8 orang $(13,33 \%)$ berpartifasi sedang dan 4 orang $(6,67 \%)$ berpartifasi rendah. Pada tahap pelaksanaan 45 orang $(75,00 \%)$ berpartipasi tinggi dalam pelaksanaan usahatani padi system tanam jajar legowo, 11 orang $(18,34 \%)$ berpartifasi sedang dan 4 orang $(6,67 \%)$ berpartifasi rendah. Pada Substansi kegiatan penyuluhan 44 orang $(73,34 \%)$ berpartifasi tinggi, 11 
orang $(18,33 \%)$ berpartifasi sedang dan 5 orang $(8,55 \%)$ berpartifasi rendah. Penyebaan informasi 43 orang (71,67\%) berpartisifasi tinggi, 11 orang $(18,33 \%)$ berpartifasi sedang dan 6 orang $(10 \%)$ berpartisifasi rendah dalam penyebaran informasi. Kemudian pada tahap evaluasi sebagian besar yaitu 45 Orang (75\%) berpartisifasi tinggi, 13 orang $(21,67)$ berpartifasi sedang dan 2 orang $(3,33 \%)$ berpartifasi rendah.

Tabel 3. Rerata Skor Partisifasi Petani dilihat dari Aspek yang dinilai

\begin{tabular}{|l|l|c|c|c|c|}
\hline \multirow{2}{*}{ No } & \multicolumn{1}{|c|}{ Aspek yang dinilai } & \multicolumn{3}{c|}{ Partisifasi } & \multirow{2}{*}{ Total } \\
\cline { 3 - 6 } & & Tinggi & Sedang & Rendah & \\
\cline { 3 - 6 } & & skor & Skor & Skor & \\
\hline 1 & Perencanaan & 144 & 16 & 4 & 164 \\
\hline 2 & Pelaksanaan Kegiatan penyuluhan & 135 & 22 & 4 & 161 \\
\hline 3 & Penyebarluasan informasi & 129 & 22 & 6 & 157 \\
\hline 4 & Tahap evaluasi & 135 & 26 & 2 & 163 \\
\cline { 2 - 6 } & Rata-rata & & & & 161.25 \\
\hline
\end{tabular}

Sumber : Data primer diolah, 2020

Dari table di atas dilihat 4 (empat) aspek yang dinilai yaitu perencanaan, pelaksanaan kegiatan penyuluhan, penyebaran informasi dan tahap evaluasi, partisifasi petani adalah tinggi yaitu 161,25

\section{Kendala-kendala Partisifasi Petani dalam Pelaksanaan Penyuluhan Usahatani Padi Sistem Tanam Jajar Legowo}

Walaupun partisifasi petani dalam kegiatan penyuluhan usahatani padi sawah system tanam jajar dengan katagori tinggi, namun masih adanya beberapa petani kurang berpartifasi dalam kegiatan tersebut.

Beberpa kendala yang dihadapi petani dalam kegiatan penyuluhan adalah diantaranya adalah sebagai berikut: berbenturan dengan kesibukan yang lain, adanya kejenuhan mengikuti penyuluhan karena membuang waktu, pemberain materi tidak sesuai dengan pola tanam yang ditanam petani dan manfaatnya dirasakan masih kurang.

Kemudian pertanyaan selanjutnya kenapa masih menanam padi dengan system yang tidak teratur, jawaban petani adalah : menanam dengan system tanam jajar memelukan waktu yang lebih banyak, membutuhkan benih yang lebih banyak, memerlukan pupuk dan tenanga kerja yang lebih banyak akhirnya berdampak pada biaya yang dkeluarkan oleh banyak.

Jawaban dari petani bisa dimaklumi bahwa petani dalam adopsi teknologi biasanya sudah mempertimbangkan aspek ekonominya. Hal ini sesuai dengan Made Suma Wedastra (1988) bahwa adopsi teknologi baru harus menberikan keuntungan dibandingkan dengan teknologi yang sudah diterapkan oleh petani.

\section{SIMPULAN DAN SARAN}

\section{Simpulan}

Dari hasil penelitian dapat disimpulkan bahwa :

1. Partisifasi petani dalam kegiatan penyuluhan usahatani padi sawah dengan system tanam jajar legowo tergolng tinggi, yaitu dengan tingkat partifasi 161,25.

2. Beberpa kendala yang dihadapi petani dalam kegiatan penyuluhan adalah diantaranya adalah: berbenturan dengan kesibukan lain, adanya kejenuhan mengikuti penyuluhan karena membuang waktu, pemberain materi tidak sesuai dengan pola tanam yang ditanam petani dan manfaatnya dirasakan masih kurang.

3. Masih banyak petani yang tidak mengadopsi teknologi tersebut, dengan alasan bahwa : menanam dengan system tanam jajar memelukan waktu yang lebih banyak, membutuhkan benih yang lebih banyak, memerlukan pupuk dan tenanga kerja yang lebih banyak akhirnya berdampak pada biaya yang dkeluarkan oleh banyak. 


\section{Saran}

Untuk meningkatkan partifasi petani dalam kegiatan penyuluhan, perlu pembinaan dan pelatihan yang lebih intensif oleh petugas penyuluh lapangan (PPL), sehingga dapat merubah prilaku petani dan mau mengadopsi teknolgi tersebut

\section{DAFTAR PUSTAKA}

Badan Penelitian dan Pengembangan Pertanian, 2007. Dirjen Pertanian Jakarta.

Masri, S. dan Effendi, S., 2010. Metode Penelitian Survai. LP3ES. Jakarta.

Mardikanto, T. 2009. Penyuluhan Pembangunan Pertanian. Sebelas Maret University Press Semarang

Permana, 1998. Teknologi Usahatani Mina Padi Azolla dengan Cara Tanam Jajar Legowo. Mimbar Serasehan Sistem Usahatani Berbasis Padi di Jawa Tengah. BPPT Unggaran.

Purwanto, S., 2008. Implmentasi kebijakan untuk pencapaian P2BN. Prosiding Seminar Apresiasi hasil penelitian Padi menunjang P2BN. Balai Besar Penelitian Tanam padi. Sukamandi

Ridwan, Lalu Wirasapta Karyadi, Nuning Juniarsih, 2019. Peningkatan Produksi. Usahatani Padi di Kecamatan Gunungsari Melalui Penyuluhan teknologi Produksi. dalam Jurnal Pengabdian Jurnal Abdi Mas TPB. Volume 1 Nomor 1 Januari 2019, p.84-90. LPPM UNRAM Mataram

Surahmad W. 2010. Dasar dan Metode Teknik Penelitian. Tarsito Bandung

Umiarsih, 2012. Jarak tanam pada Budidaya Padi Tanam Jajar Legowo. Internet dounlod 12 Agustus 2012.

Wedastra,M.S. 1988. Peranan Teknologi Baru dalam Pembangunan Pertanian. Majalah ilmiah Koertis Wil. VIII Denpasar.

Wedastra,M.S. 2009. Buku Ajar Penyuluhan Pertanian. Fakultas Peranian Universitas Mahasaraswati Mataram 